\title{
Almond consumption improves satiety and ectopic fat content relative to a high-carbohydrate food: A pilot RCT in minority adults
}

\author{
Marie-Pierre St-Onge ${ }^{1}, \underline{A y a n n a}$ Campbell $^{1}$ and Arindam RoyChoudhury ${ }^{2}$ \\ ${ }^{1}$ Columbia University, New York, USA and \\ ${ }^{2}$ Cornell University, New York, USA
}

\section{Abstract}

Nut consumers have lower body weight and are at lower cardiovascular disease risk than non-consumers. Interestingly, minority adults, who have the highest prevalence of obesity and are at disproportionate risk of cardiovascular disease, have low nut intakes. The goal of this study was to test whether consumption of almonds, compared to low-fat/high-carbohydrate cereal bars (LF-HC), as a supplement for $24 \mathrm{wk}$, would improve appetite regulation and body composition in Blacks and Hispanics. Twenty-nine adults, BMI > $25 \mathrm{~kg} / \mathrm{m}^{2}$, age $30-65 \mathrm{y}$, were recruited and randomized to consume either almonds or LF-HC providing $17.5 \%$ of their estimated energy requirements as part of their regular diet. A total of 17 adults completed the study, 9 men and 8 women; 7 of whom were randomized to almond consumption ( 4 men, 3 women), and 10 to LF-HC consumption ( 5 men, 5 women). Outcome variables included appetite-regulating hormones and inflammatory markers, which were measured from fasting blood samples taken at baseline, week 12, and endpoint. Body composition was measured by magnetic resonance imaging at baseline and endpoint. Data were analyzed using linear mixed model with treatment, time, and their interaction as predictor variables; age, race, sex, and baseline BMI as covariates; and participant ID as a random effect variable. Peptide YY concentrations were higher in the almond group compared to $\mathrm{LF}-\mathrm{HC}$ (time $\mathrm{x}$ treatment interaction at $12 \mathrm{wk}, \mathrm{P}<0.001 ; 24 \mathrm{wk}, \mathrm{P}=0.13$ ). Glucagon-like peptide 1 concentrations were higher in the almond group compared to LF-HC (time $\mathrm{x}$ treatment interaction at $12 \mathrm{wk}, \mathrm{P}=0.10 ; 24 \mathrm{wk}, \mathrm{P}=0.015$ ). Ghrelin levels decreased in LF-HC compared to the almond group at $12 \mathrm{wk}$ but not $24 \mathrm{wk}$ (time $\mathrm{x}$ treatment interaction at $12 \mathrm{wk}, \mathrm{P}=0.017 ; 24 \mathrm{wk}, \mathrm{P}=0.23$ ). There was a slight trend for a time $\mathrm{x}$ treatment interaction on body weight $(\mathrm{P}=0.14$; change in almond $=0.6 \pm 1.8 \mathrm{~kg} ; \mathrm{LF}-\mathrm{HC}=1.9 \pm$ $2.7 \mathrm{~kg})$. There was a time $\mathrm{x}$ treatment interaction on intermuscular adipose tissue $\left(\mathrm{P}=0.013\right.$; change in almond $=-0.10 \pm 0.14 \mathrm{~cm}^{3}$; $\left.\mathrm{LF}-\mathrm{HC}=0.04 \pm 0.07 \mathrm{~cm}^{3}\right)$. None of the measured inflammatory markers (C reactive protein, interleukin-6, and tumor necrosis factor) were affected by the dietary interventions. Despite the lack of profound body composition changes, daily almond intake for 24 wk, within the usual diet, ameliorated satiety and ectopic fat deposition, suggesting a potential role of nut consumption in the context of a weight reduction program in minority adults. Our data support further exploration of the health effects of nut consumption in this population.

\section{Conflict of Interest}

This work was funded in part by the Almond Board of California. 